\title{
Middle-atmospheric zonal and meridional wind profiles from polar, tropical and midlatitudes with the ground-based microwave Doppler wind radiometer WIRA
}

\author{
R. Rüfenacht ${ }^{1}$, A. Murk ${ }^{1}$, N. Kämpfer ${ }^{1}$, P. Eriksson ${ }^{2}$, and S. A. Buehler ${ }^{3, *}$ \\ ${ }^{1}$ Institute of Applied Physics, University of Bern, Bern, Switzerland \\ ${ }^{2}$ Department of Earth and Space Sciences, Chalmers University of Technology, Gothenburg, Sweden \\ ${ }^{3}$ Division of Space Technology, SRT, Luleå University of Technology, Kiruna, Sweden \\ *now at: Meteorological Institute, Center for Earth System Research and Sustainability, University of Hamburg, \\ Hamburg, Germany
}

Correspondence to: R. Rüfenacht (rolf.ruefenacht@iap.unibe.ch)

Received: 4 July 2014 - Published in Atmos. Meas. Tech. Discuss.: 28 July 2014

Revised: 10 November 2014 - Accepted: 23 November 2014 - Published: 18 December 2014

\begin{abstract}
WIRA is a ground-based microwave Doppler spectroradiometer specifically designed for the measurement of profiles of horizontal wind in the upper stratosphere and lower mesosphere region where no other continuously running measurement technique exists. A proof of principle has been delivered in a previous publication. A technical upgrade including a new high-frequency amplifier and sideband filter has improved the signal to noise ratio by a factor of 2.4 . Since this upgrade the full horizontal wind field comprising zonal and meridional wind profiles is continuously measured. A completely new retrieval based on optimal estimation has been set up. Its characteristics are detailed in the present paper.

Since the start of the routine operation of the first prototype in September 2010, WIRA has been measuring at four different locations at polar, mid- and tropical latitudes $\left(67^{\circ} 22^{\prime} \mathrm{N} / 26^{\circ} 38^{\prime} \mathrm{E}, 46^{\circ} 57^{\prime} \mathrm{N} / 7^{\circ} 26^{\prime} \mathrm{E}, 43^{\circ} 56^{\prime} \mathrm{N} / 5^{\circ} 43^{\prime} \mathrm{E}\right.$ and $21^{\circ} 04^{\prime} \mathrm{S} / 55^{\circ} 23^{\prime} \mathrm{E}$ ) for time periods between 5.5 and 11 months. The data presented in this paper are daily average wind profiles with typical uncertainties and resolutions of 10 to $20 \mathrm{~m} \mathrm{~s}^{-1}$ and 10 to $16 \mathrm{~km}$, respectively. A comparison between the data series from WIRA and European Centre for Medium-Range Weather Forecasts (ECMWF) model data revealed agreement within $10 \%$ in the stratospheric zonal wind. The meridional wind profiles agree within their error bars over the entire sensitive altitude range of WIRA. However, significant differences in the mesospheric zonal wind speed of up to $50 \%$ have been found.
\end{abstract}

\section{Introduction}

Wind is a key parameter for the characterisation of the atmosphere and its dynamics on every altitude level. Recent studies have also demonstrated the influence of middleatmospheric dynamics on tropospheric weather patterns (e.g. Baldwin and Dunkerton, 2001; Hardiman et al., 2011). However, in the middle atmosphere the only continuous source of wind data so far has been models. A gap region with a lack of measured wind information exists in the middle atmosphere between approximatively 10 and $10^{-2} \mathrm{hPa}$. Very few measurement techniques covering parts of this altitude range are or have been operated on a campaign basis. Measurements from Rayleigh lidars (Baumgarten, 2010) and rocket-aided techniques (e.g. Goldberg et al., 2004; Chu et al., 2007; Finger et al., 1975) have been presented. Different upper atmosphere radar techniques provide data above $70 \mathrm{~km}$ altitude. Under special atmospheric conditions measurement ranges extending as low as $60 \mathrm{~km}$ have been reported (Jacobi et al., 2007; Hoffmann et al., 2007; Nicolls et al., 2010). For a limited time, microwave wind measurements have been performed from space by the microwave limb sounder SMILES (Baron et al., 2013). A more extended overview of the different wind measurement techniques with their key characteristics and their sensitive altitude range can be found in Rüfenacht et al. (2012).

A first prototype of the wind radiometer WIRA has demonstrated the potential of ground-based microwave 
Doppler wind radiometry (Rüfenacht et al., 2012). Compared to the other techniques mentioned above, ground-based microwave radiometry has the advantage of allowing the acquisition of long continuous time series of wind profiles. Indeed, the operation of such instruments can be highly automated and remotely controlled. Moreover, microwave radiometry is not dependent on daylight conditions and is only weakly affected by cloud cover.

Since the first prototype of WIRA, described by Rüfenacht et al. (2012), significant technical developments as well as a completely new retrieval algorithm have greatly enhanced the quality of the wind estimates. Together with the data obtained on extended measurement campaigns held at polar, tropical and midlatitudes, this gives us the ability to draw meaningful conclusions on the difference between measured middle-atmospheric wind and data from models.

The first part of the present publication will describe the key characteristics of the receiver, focusing on the new technical developments; the second part introduces the new optimal estimation retrieval. In the third part wind data from the different measurement campaigns are presented and compared to model data from ECMWF.

\section{The instrument}

The ground-based wind radiometer WIRA (see Fig. 1) is a $142 \mathrm{GHz}$ heterodyne radiometer measuring Doppler shifts in the emission spectrum of atmospheric ozone in order to derive middle-atmospheric wind profiles. In the routine operation the duration of one measurement cycle is $60 \mathrm{~s}$. Such a cycle contains the measurement of the signals from the two calibration targets (ambient temperature load and sky at zenith) as well as from two or four cardinal directions for the wind retrieval. The wind retrieval combines the calibrated spectra obtained at two opposite viewing directions (i.e. east and west for zonal and north and south for meridional wind). In this way drifts and fluctuations in reference frequency oscillators on timescales larger than $1 \mathrm{~min}$ are removed in the wind retrieval.

The prototype of the instrument as well as its operation mode and calibration scheme is described in detail in Rüfenacht et al. (2012). A block diagram of the current version of WIRA is shown in Fig. 2. Since the first prototype different frequency sources have been replaced, mainly for the sake of operational robustness. In addition, this led to minor improvements in the total frequency stability. A reassessment of the frequency stability was performed after the last upgrade by using a GPS signal as frequency reference. With this setup Allan standard deviation measurements revealed the results displayed in Fig. 3. As drifts and long-term frequency instabilities on timescales longer than one measurement cycle are compensated by the comparison of spectra from opposite viewing directions in the wind retrieval, we can state that the maximum frequency error induced by reference oscillator in-

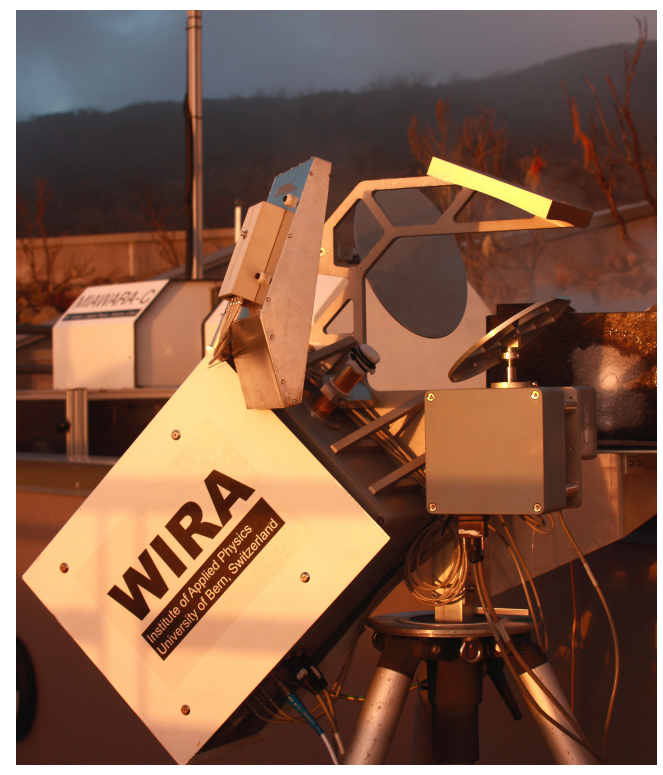

Figure 1. WIRA's frontend during its operation at the Observatoire du Maïdo on La Réunion island.

stabilities is smaller than $14 \mathrm{~Hz}$. This leads to a wind error of a few centimetres per second only, and can thus safely be neglected in the error analysis.

For reasons of compactness and reliability, especially when measuring under harsh conditions, WIRA cannot use an optical sideband filter. Therefore, the instrument was initially designed as a double sideband radiometer. Benefiting from recent advances in the construction of low noise amplifiers (LNAs) at frequencies beyond $100 \mathrm{GHz}$, WIRA was transformed to a single sideband radiometer in summer 2012 by adding a D-band LNA, a waveguide bandpass filter and an isolator before the radio frequency (RF) entrance of the mixer. S-parameter measurements using a high-frequency vector network analyser revealed a good sideband separation achieved by the new RF components. The image sideband centred around $149.576 \mathrm{GHz}$ is rejected down to $50 \mathrm{~dB}$ and the reflections in the signal sideband are in the order of $-30 \mathrm{~dB}$ only.

Noise temperature tests with liquid nitrogen calibrations revealed that the upgrade had reduced the noise temperature from $880 \mathrm{~K}$ double sideband to $740 \mathrm{~K}$ single sideband. As the contribution of the image sideband in a double sideband receiver can be regarded as noise, the change in the receiver noise temperature corresponds to a 2.4 times better signal to noise ratio for the upgraded instrument.

The optics of WIRA had been designed for the measurement of the complete horizontal wind field, i.e. for the measurement of the zonal and meridional wind components. However, because of the relatively low signal to noise ratio, the meridional wind, which is generally small, had not been routinely measured until summer 2012 in order to save integration time to get a more accurate estimate of the zonal 


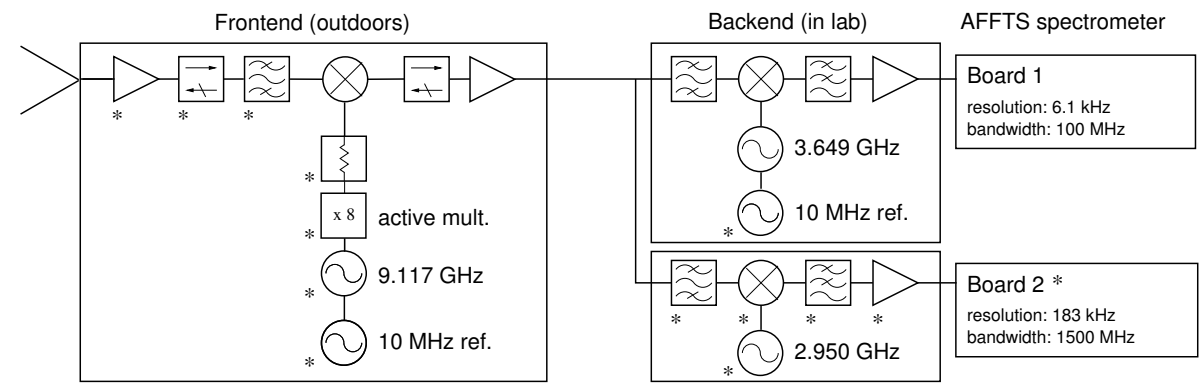

Figure 2. Block diagram of the upgraded receiver electronics of WIRA. For the wind retrieval described in this paper only the data from the narrow band spectrometer (board 1) are used. The components that have been modified or added since the prototype described in Rüfenacht et al. (2012) are marked with an asterisk.

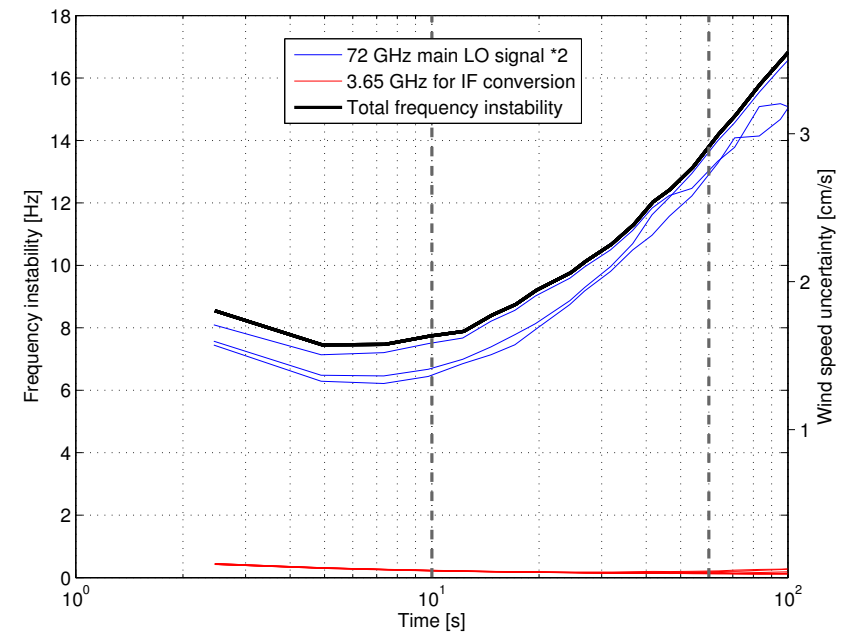

Figure 3. Influence of the fluctuations and drifts of the frequency sources on the total frequency uncertainty of the measured signal. The instability of the $72 \mathrm{GHz}$ local oscillator (LO) frequency has to be multiplied by 2 as the subharmonic mixer uses the second harmonic of the LO signal. The grey vertical lines at 10 and $60 \mathrm{~s}$ mark the minimum integration time per single measurement and the duration of one measurement cycle. The second $y$ axis indicates the influence of the instabilities of the frequency sources on the uncertainty of the retrieved wind velocity.

wind. After the instrumental upgrade WIRA routinely measures both the zonal and the meridional wind components.

\section{Optimal estimation wind retrieval}

A first approach for a wind retrieval from spectra measured by a ground-based microwave radiometer was presented in Rüfenacht et al. (2012). This somewhat simplistic approach, which assumed five completely independent atmospheric levels, has now been replaced by a retrieval algorithm based on full radiative transfer modelling of the atmosphere coupled with the optimal estimation method for inverse problems (Rodgers, 2000).
The signal observed by a ground-based microwave radiometer is a superposition of emissions and absorptions at different atmospheric altitudes along the line of sight path $s$. The brightness temperature $T_{\mathrm{b}}$ measured at the frequency $v$ can be described by

$$
\begin{aligned}
& T_{\mathrm{b}}(v)=T_{\mathrm{b} 0}(v) e^{-\tau\left(s_{0}\right)}+\ldots \\
& \quad \int_{0}^{s_{0}} k_{\mathrm{a}}\left(v, p(s), T(s), n_{i}(s), \Delta v(s), \ldots\right) \cdot T(s) e^{-\tau(s)} \cdot \mathrm{d} s,
\end{aligned}
$$

where the opacity $\tau$ from the path point $s$ to the ground can be written as

$$
\tau(s)=\int_{0}^{s} k_{\mathrm{a}}\left(v, p\left(s^{\prime}\right), T\left(s^{\prime}\right), n_{i}\left(s^{\prime}\right), \Delta v\left(s^{\prime}\right), \ldots\right) \cdot \mathrm{d} s^{\prime} .
$$

$T_{\mathrm{b} 0}$ is the microwave background radiation entering the atmosphere, $s_{0}$ is the assumed upper boundary of the atmosphere, $T$ is the physical temperature and $k_{\mathrm{a}}$ is the absorption/emission coefficient depending on the local conditions of the atmosphere (pressure $p$, temperature $T$, the concentration of the different species contributing to absorption at this frequency $n_{i}$ ). The influence on $k_{\mathrm{a}}$ by the Doppler shift $\Delta v\left(s^{\prime}\right)$ induced by the line of sight wind at each altitude can be exploited to determine wind profiles with receivers like WIRA.

The radiative transfer equation (Eq. 1) together with the modelling of the signal treatment by the receiver builds the so-called forward model $F$ of our retrieval. The measurement situation can be summarised to

$\boldsymbol{y}=F(\boldsymbol{x}, \boldsymbol{b})+\boldsymbol{\epsilon}$.

The vector $\boldsymbol{y}$ contains the calibrated brightness temperature spectra measured by WIRA ( $T_{\mathrm{b}}(v)$ in Eq. 1$), \boldsymbol{x}$ is composed of quantities to be retrieved (mainly atmospheric profiles) while $\boldsymbol{b}$ is a set of additional forward model parameters and $\boldsymbol{\epsilon}$ is the measurement noise. In the case of a non-linear forward model as encountered here, Eq. (3) is linearised:

$\boldsymbol{y}=F\left(\hat{\boldsymbol{x}}_{i}, \boldsymbol{b}\right)+\mathbf{K}\left(\boldsymbol{x}-\hat{\boldsymbol{x}}_{i}\right)+\boldsymbol{\epsilon}$, 

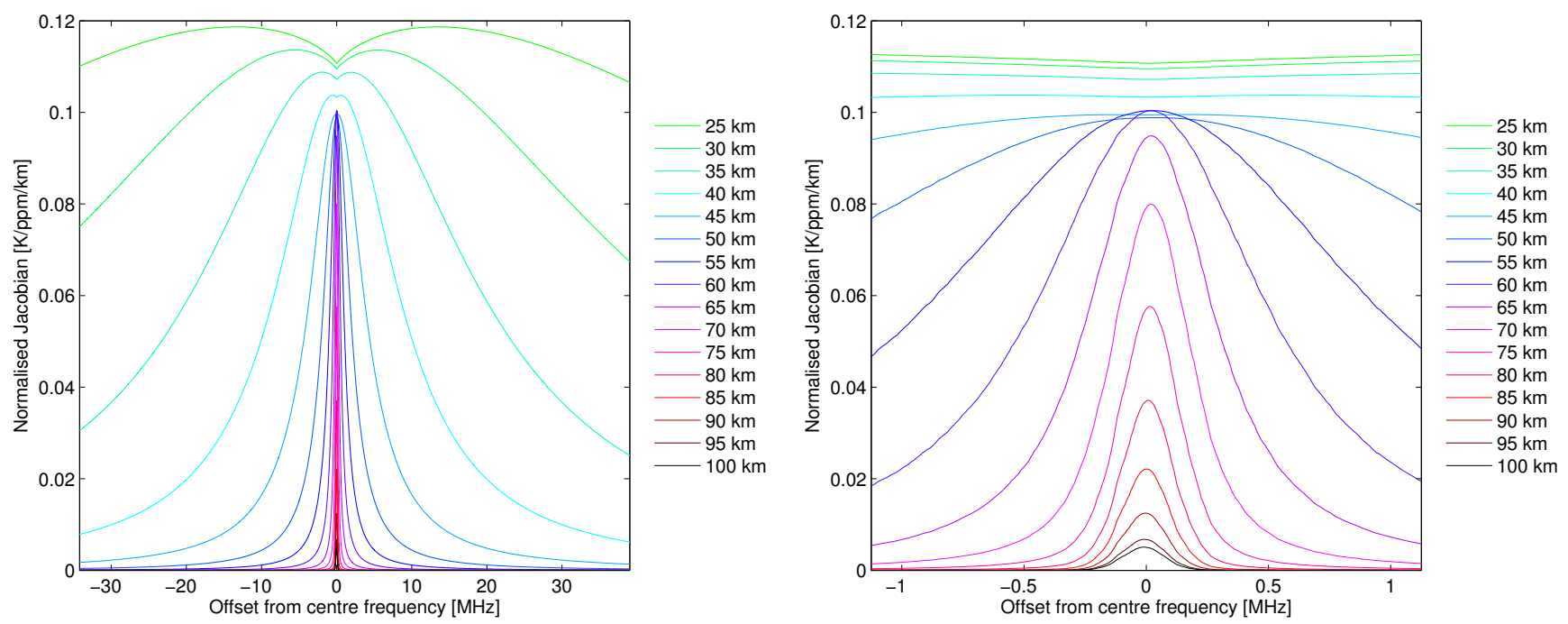

Figure 4. Rows of the Jacobian describing WIRA's ozone retrieval normalised by the layer thickness of the retrieval grid for observations at $22^{\circ}$ elevation. Full usable spectrometer bandwidth (left) and zoom on the central channels (right).

with $\hat{\boldsymbol{x}}_{i}$ being the retrieval solution after the $i$ th iteration. The Jacobian matrix $\mathbf{K}$ contains the partial derivatives of the forward model with respect to the parameters to be retrieved:

$\mathbf{K}=\left.\frac{\partial F}{\partial \boldsymbol{x}}\right|_{\hat{\boldsymbol{x}}_{i}, \boldsymbol{b}}$.

In most situations commonly encountered in microwave remote sensing of the atmosphere, $\boldsymbol{x}$ mainly contains the profiles of different atmospheric species or of the temperature (e.g. Palm et al., 2010; Stähli et al., 2013; Tschanz et al., 2013). In this case the rows of the Jacobian look similar to the ones in WIRA's ozone retrieval shown in Fig. 4. They are positive and symmetric around the centre frequency of the emission line, meaning that a higher ozone concentration leads to higher measured brightness temperatures at all frequencies. Because of pressure broadening, the higher altitudes (low pressure) mainly contribute to the signal in the central channels whereas lower altitudes (high pressure) also contribute to the signal on the wings of the measured spectrum.

In the situation of wind retrievals, the functions in the rows of $\mathbf{K}$ are of a different type (Fig. 5). The effect of the line of sight wind profile can be thought of as applying a frequency shift to the absorption coefficients of the contributing molecules at each altitude. Therefore, in contrast to species or temperature profile retrievals, where the effect on the measured spectra is basically a shift in intensity space, the effect of wind can be understood as a shift of parts of the spectra in frequency space. This manifests itself in the point symmetric behaviour of the rows of the Jacobian around the point (centre frequency, 0 ) being all negative on one side of the centre frequency and all positive on the other side. In practice a major advantage of this behaviour is that calibration errors do not influence the wind retrieval as long as they can be regarded as frequency independent. In our narrow band measurement situation this can be assumed to be true and calibration errors can be thought of as causing an offset or stretching of the spectrum in the intensity dimension. Due to pressure broadening, the functions in the rows of $\mathbf{K}$ corresponding to altitudes below $30 \mathrm{~km}$ are nearly frequency independent over the range covered by our spectrometer and their amplitude is very small. This illustrates the lower limit of the altitude range that WIRA is sensitive to. On the other hand, the small amplitudes above $85 \mathrm{~km}$ indicate that not much information about these altitudes is contained in the measurements from WIRA.

Figures 4 and 5 also give an indication of the strengths of the effect of ozone variations and wind on the measured spectra. For the ozone retrieval the values of $\mathbf{K}$ normalised by the layer thickness of the retrieval grid are typically in the order of $0.1 \mathrm{~K} \mathrm{ppm}^{-1} \mathrm{~km}^{-1}$. With ozone variations in the atmosphere being in the order of $1 \mathrm{ppm}$ they influence the measured spectra in the order of $0.1 \mathrm{~K} \mathrm{~km}^{-1}$. For wind the normalised values of the Jacobian lie typically around $0.03 \mathrm{mK}\left(\mathrm{m} \mathrm{s}^{-1}\right)^{-1} \mathrm{~km}^{-1}$ and the atmospheric variations are in the order of $100 \mathrm{~m} \mathrm{~s}^{-1}$, i.e. the influence on the measured spectra is of the order of $3 \mathrm{mK} \mathrm{km}^{-1}$. Therefore we can state that the effect of wind variations on the measured brightness temperature spectra is approximatively thirty times smaller than the effect of typical ozone variations. However, the wind retrieval is fairly independent of the ozone retrieval as will be shown in the subsection "Evaluation of possible sources for bias errors" of Sect. 4.3.

In order to progress from the measured brightness spectra to the state of the atmosphere (wind profile, ozone profile, etc.), the inverse problem has to be solved, i.e. Eq. (4) has to be inverted. However, this is an ill-posed problem, so statisti- 

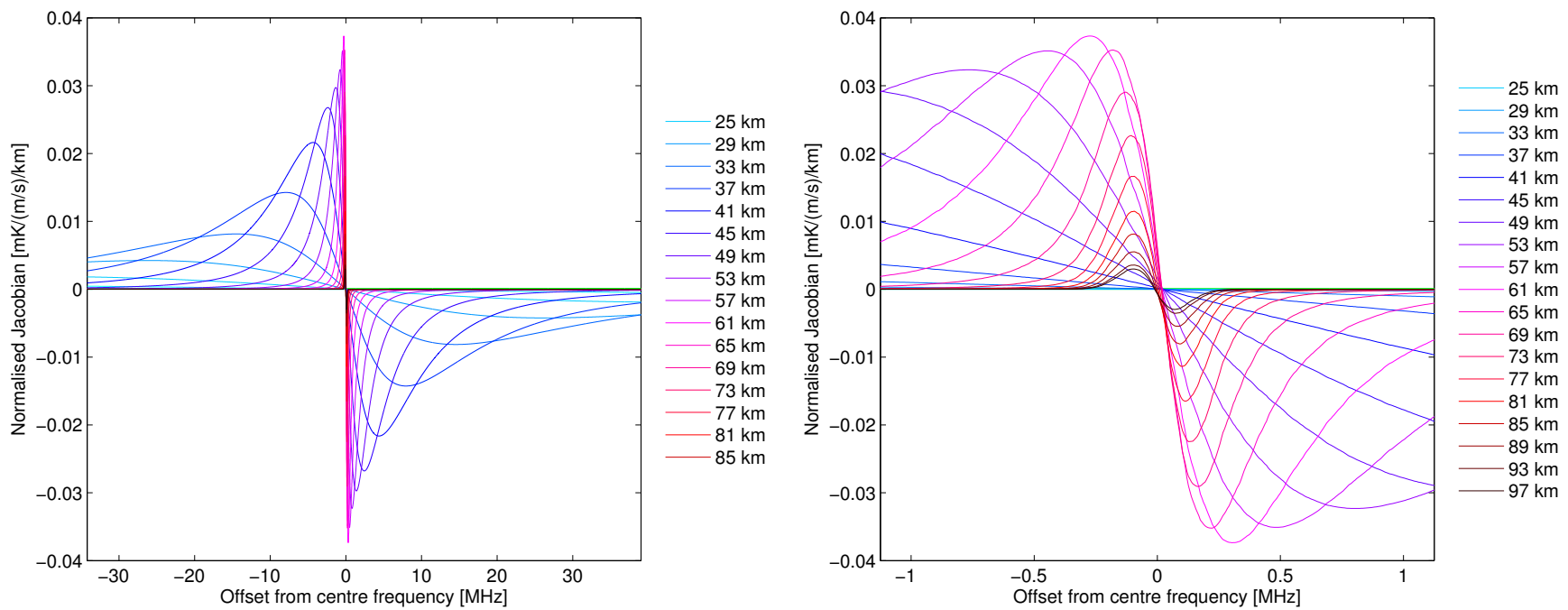

Figure 5. Rows of the Jacobian describing WIRA's horizontal wind retrieval normalised by the layer thickness of the retrieval grid for observations at $22^{\circ}$ elevation. Full usable spectrometer bandwidth (left) and zoom on the central channels (right).

cal a priori constraints need to be imposed in order to obtain a realistic solution. The "optimal" solution in the sense of Rodgers (2000) minimises the cost function

$$
\begin{aligned}
\chi^{2} & =\left(\boldsymbol{x}-\boldsymbol{x}_{\mathrm{a}}\right)^{\mathrm{T}} \mathbf{S}_{\mathrm{a}}^{-1}\left(\boldsymbol{x}-\boldsymbol{x}_{\mathrm{a}}\right) \ldots \\
& +(\boldsymbol{y}-F(\boldsymbol{x}, \boldsymbol{b}))^{\mathrm{T}} \mathbf{S}_{\epsilon}^{-1}(\boldsymbol{y}-F(\boldsymbol{x}, \boldsymbol{b})),
\end{aligned}
$$

where $\boldsymbol{x}_{\mathrm{a}}$ contains prior knowledge about the behaviour of the atmosphere (in form of realistic species or wind profiles) along with some statistics mapped into the covariance matrix $\mathbf{S}_{\mathrm{a}}$, which defines the strengths of the constraints and the correlation between different parameters/altitude levels. The wind retrieval is of non-linear type so that the solution has to be found iteratively. Applying the Levenberg-Marquardt iteration scheme (Marquardt, 1963; Press et al., 2007), the iteration step to be taken reads:

$$
\begin{array}{r}
\hat{\boldsymbol{x}}_{i+1}=\hat{\boldsymbol{x}}_{i}+\left((1+\gamma) \mathbf{S}_{\mathrm{a}}^{-1}+\mathbf{K}_{i}^{\mathrm{T}} \mathbf{S}_{\epsilon}^{-1} \mathbf{K}_{i}\right)^{-1} \cdots \\
\cdot\left(\mathbf{K}_{i}^{\mathrm{T}} \mathbf{S}_{\epsilon}^{-1}\left(\boldsymbol{y}-F\left(\hat{\boldsymbol{x}}_{i}, \boldsymbol{b}\right)\right)-\mathbf{S}_{\mathrm{a}}^{-1}\left(\hat{\boldsymbol{x}}_{i}-\boldsymbol{x}_{\mathrm{a}},\right)\right)
\end{array}
$$

with $\hat{\boldsymbol{x}}_{i}$ being the retrieved solution after the $i$ th iteration step. The damping factor $\gamma$ is varied according to Press et al. (2007).

\section{WIRA's retrieval setup}

An extension of the radiative transfer simulation and inversion software package ARTS/QPACK (Eriksson et al., 2011, 2005) made it usable for wind retrievals from WIRA data. To allow this, the Atmospheric Radiative Transfer Simulator (ARTS) now includes an input variable for the wind field, which is used to calculate Doppler shifts in the radiative transfer calculations, which are then handed down to the absorption calculation.

ARTS has two different ways to deal with the absorption calculation, "lookup", or "on the fly", which are discussed in Buehler et al. (2011). In the first case, absorption is precalculated and stored in a lookup table. When Doppler shifts are present, absorption is needed for slightly different frequencies than the precalculated ones, and thus has to be interpolated. This approach is similar to the approach used in the initial simple wind retrievals by Rüfenacht et al. (2012). It can however pose numerical difficulties, since the dependence of the measured spectra on the Doppler shift is quite nonlinear.

In the second case, "on the fly" absorption, the Doppler shift calculation is exact, since absorption is calculated completely from scratch (line by line) inside the radiative transfer calculation, and this calculation is simply done for slightly shifted frequencies compared to the zero wind case. It is this option that was used for the new retrievals presented here. For both absorption cases, wind Jacobians are calculated by ARTS semi-analytically, i.e. the difference in absorption due to wind is propagated analytically through the radiative transfer, following the mathematical chain rule for derivatives. The general approach is described in Buehler et al. (2005).

WIRA's retrieval is a combined retrieval that simultaneously determines wind, ozone, (continuum) water vapour (according to Rosenkranz, 1993) and a second order polynomial for basic corrections of baseline issues. The oxygen continuum according to Rosenkranz (1998) and the nitrogen self-broadening according to Liebe et al. (1993) are included in the model but are not retrieved. In our measurement scheme the water vapour can basically be regarded as a correction term for tropospheric absorption and emission. To a large extent also calibration errors are absorbed by this 


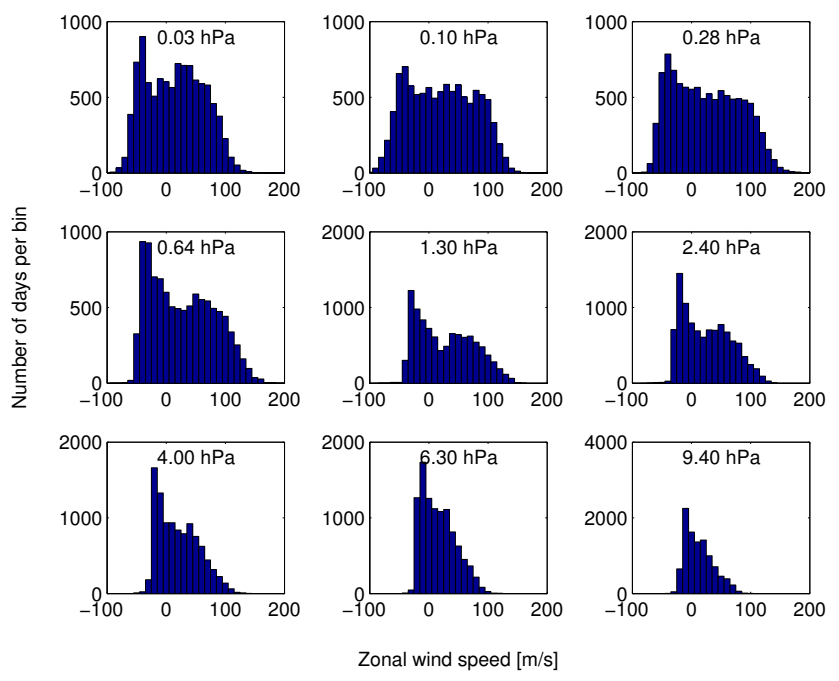

Figure 6. Distribution of zonal wind speeds on different altitude levels between $72 \mathrm{~km}$ (top left panel) and $32 \mathrm{~km}$ (bottom right) according to ECMWF operational analysis data. In this example 6 years of data for Bern have been used.

term. Calibration inaccuracies are due to the assumption of a homogeneous troposphere in the tipping curve gain calibration process in cases where this is not exactly true (see Rüfenacht et al., 2012; Schneebeli and Mätzler, 2009). The retrieval is independently applied to each direction, with wind blowing towards (away from) the receiver defined as positive (negative). The zonal and meridional wind velocities are thereafter calculated from the difference between the retrieved wind profiles for east and west, or for north and south, respectively. This procedure largely excludes inaccuracies of frequency sources, slight frequency dependencies of possible gain linearity errors or influences of the baseline to propagate into the resulting wind speeds.

Ozone profiles have long been regarded as a by-product and have not been analysed in depth. First intercomparisons with the ozone radiometer GROMOS (Dumitru et al., 2006) and the microwave limb sounder (MLS) on the Aura satellite (Waters et al., 2006), however, revealed that the ozone profile retrieval can also deliver useful results. Further analyses, especially assessing possible intensity calibration errors, will, however, be needed to validate the ozone profiles.

For the results presented in this paper only the data from WIRA's narrow band spectrometer with a resolution of $6.1 \mathrm{kHz}$ and a bandwidth of $100 \mathrm{MHz}$ have been used.

\subsection{A priori constraints}

A cautious setup of the a priori constraints is an important part of any optimal estimation retrieval. Indeed, this should guarantee meaningful results of the ill-posed problem while the influence on the resulting profile must be small compared to the influence of the actual measurement. The algorithm assumes a Gaussian distribution of the climatological inputs

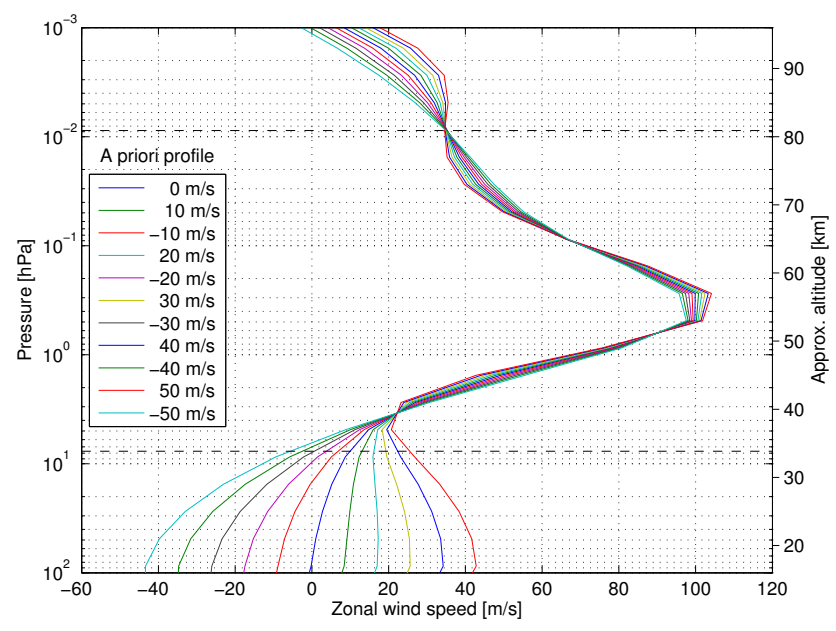

Figure 7. Influence of different choices of constant a priori wind profiles (indicated in the legend box) on the retrieval result for a real measurement example (23 November 2013). The dashed horizontal lines represent the limits where the measurement response is higher than 0.8 . Within this altitude range the influence of the choice of the a priori profile is small.

building the a priori constraints. However, the distribution of wind speeds is often far from Gaussian, as shown by the example of 6 years of zonal wind data from ECMWF for midlatitudes in Fig. 6. The dual peak regime might be related to sudden stratospheric warming events as analogously proposed by Angot et al. (2012) for the temperature distribution. Therefore the non-Gaussicity is expected to be even stronger when considering only the winter months.

For this reason we chose a temporally constant zero wind a priori profile together with a relatively large variance:

$\sqrt{\operatorname{diag}\left(\mathbf{S}_{\mathrm{a}_{u, v}}\right)}=4 \cdot \boldsymbol{\sigma}_{u, v}$,

where $\sigma_{u, v}$ is the temporal standard deviation of daily average zonal or meridional profiles from ECMWF, depending on location. The values for $\sigma_{u}$ typically lie around $20 \mathrm{~m} \mathrm{~s}^{-1}$ at $10 \mathrm{hPa}$ and $40 \mathrm{~m} \mathrm{~s}^{-1}$ at $1 \mathrm{hPa}$, whereas $\sigma_{v}$ takes values in the order of $10 \mathrm{~m} \mathrm{~s}^{-1}$ at $10 \mathrm{hPa}$ and $16 \mathrm{~m} \mathrm{~s}^{-1}$ at $1 \mathrm{hPa}$, except at tropical latitudes where they are smaller. The correlation length for the construction of the full covariance matrix has been chosen to be 0.5 pressure decades, i.e. $8 \mathrm{~km}$. For ozone and water vapour seasonally varying a priori profiles have been used while the temperature profile is taken from the daily average middle-atmospheric measurements from Aura MLS (Waters et al., 2006) combined with daily ECMWF data. This retrieval setup can suppress oscillations and guarantees realistic output profiles while the influence of the a priori profile is kept minimal, as shown in Fig. 7. Wind profiles retrieved with a priori profiles differing by $100 \mathrm{~m} \mathrm{~s}^{-1}$ vary by not more than $8 \mathrm{~m} \mathrm{~s}^{-1}$ in the region with high mea- 

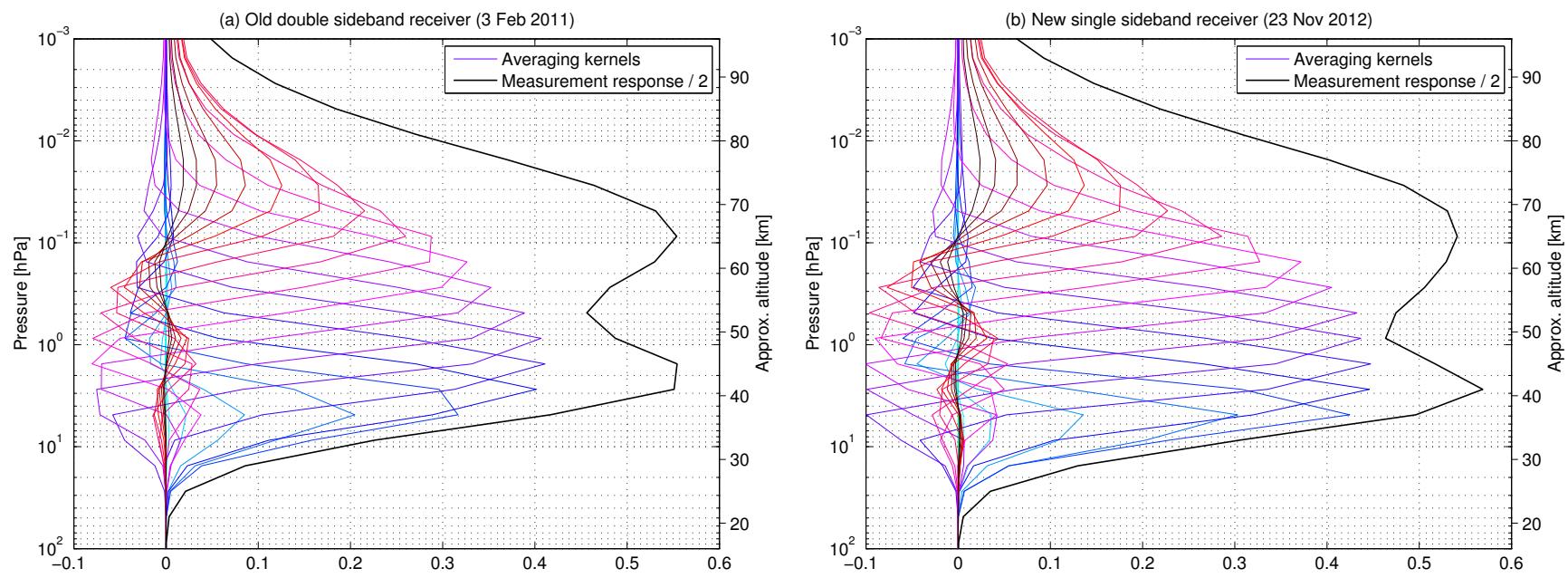

Figure 8. Typical sets of WIRA wind averaging kernels and measurement response for the old double sideband (left) and the new single sideband receiver (right).

surement response ${ }^{1}$. Therefore we can state that retrieval results are not significantly biased even in situations where the zero wind a priori assumption is far from the real state of the atmosphere.

\subsection{Altitude information and retrieval diagnostics}

In optimal estimation techniques the averaging kernel matrix A characterises the response of the retrieved profile $\hat{\boldsymbol{x}}$ to the "true" profile $\boldsymbol{x}$, i.e. $\mathbf{A}=\partial \hat{\boldsymbol{x}} / \partial \boldsymbol{x}$. The rows of $\mathbf{A}$, which are also referred to as averaging kernels, thus describe the sensitivity of a certain altitude level to perturbations from other levels. It can be shown that

$\hat{\boldsymbol{x}}=\boldsymbol{x}_{\mathrm{a}}+\mathbf{A}\left(\boldsymbol{x}-\boldsymbol{x}_{\mathrm{a}}\right)$.

Thus the sum of the rows of $\mathbf{A}$, called measurement response, indicates to which extent the actual measurement contributes to the retrieval solution and how large the influence of the a priori is at the respective altitude. The averaging kernels and the measurement response of WIRA's wind retrieval are plotted in Fig. 8. The values for the single sideband receiver shown in Fig. 8b are based on data measured with half of the integration time on the sky compared to Fig. 8a because not only the zonal but also the meridional wind was measured at this time.

The difference between the peak altitude of the averaging kernels and the nominal altitude of the respective level gives an indication of the altitude accuracy of the retrieval. As an estimator for the altitude resolution the full width at half maximum of the averaging kernels can be used.

In the post-processing of the wind retrieval data three conditions have been used to define the trustable altitude range of

\footnotetext{
${ }^{1}$ For the definition of the measurement response, please refer to Sect. 4.2.
}

the wind data from WIRA: the measurement response must be higher than 0.8 , the altitude resolution smaller than $20 \mathrm{~km}$, and the altitude accuracy better than $4 \mathrm{~km}$. Data outside this range are disregarded. Figure 9 gives an overview of the altitude dependence of these quantities in typical measurement situations.

When the single and double sideband receiver modes in Figs. 8 and 9 are compared, it appears that the averaging kernels for the single sideband receiver are slightly sharper, that its trustable altitude region is a little larger and that the altitude resolution has improved by $1.5 \mathrm{~km}$ on average. The biggest difference between the single and double sideband modes, however, appears in the wind estimation error described in the next section.

\subsection{Error analysis}

The optimal estimation technique as described by Rodgers (2000) offers the diagnostic quantities of the smoothing and observation error to give estimates of the uncertainty of the retrieved profile.

The estimates for the smoothing and observation errors provided by the optimal estimation method might be biased by the choice of the a priori covariance. However, the smoothing error basically delivers the same information as the averaging kernels A shown in Fig. 8 and can thus be omitted as long as in intercomparisons the profiles to which WIRA is compared are convolved with A. The observation error describes the fluctuation of the resulting profiles due to measurement noise. Therefore a more direct and robust way to estimate it is by means of Monte Carlo simulations.

For four sample days synthetic spectra have been calculated by radiative transfer modelling of the atmosphere from sample profiles of wind, ozone and water vapour. Noise corresponding to different typical noise levels of WIRA mea- 

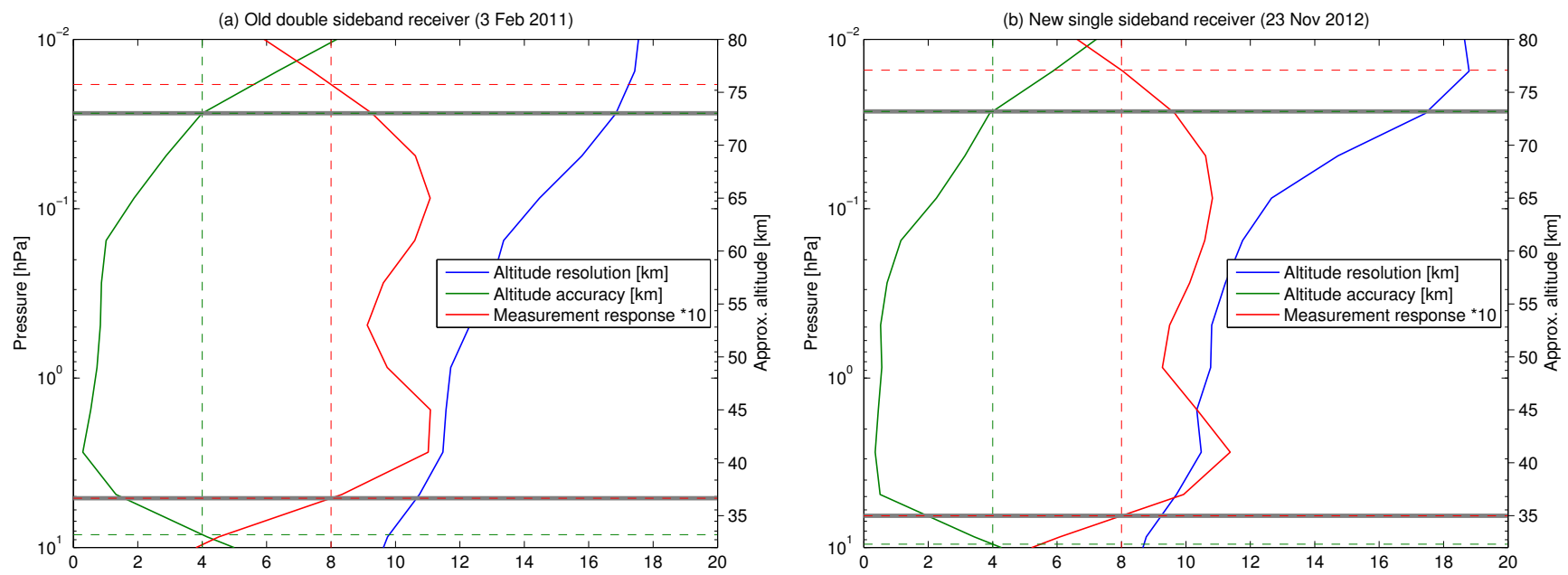

Figure 9. Typical altitude dependence of altitude resolution, altitude accuracy and measurement response of WIRA's wind retrieval in the double (left) and single sideband mode (right). The horizontal grey lines denote the limits of the trustable altitude range. The dashed lines mark the limits defined by the individual conditions.

surements was added to these spectra before they were fed into the retrieval algorithm to test its ability to reproduce the "true" state of the atmosphere. Results are shown in Figs. 10 and 11. Within the trustable altitude range the wind profile is well represented on average. The standard deviation of the single retrievals plotted in Fig. 12 is an estimator for the uncertainty in the wind retrieval. It is dependent on the signal to noise ratio of the input spectrum, which depends on the version of the receiver used to measure the emission line. Under normal measurement conditions with zenith opacities below approximately 0.3 (this corresponds to a sky containing no thick liquid water clouds), the error ranges from 16 to $25 \mathrm{~m} \mathrm{~s}^{-1}$ for the old double sideband receiver and from 12 to $20 \mathrm{~m} \mathrm{~s}^{-1}$ for the new single sideband receiver.

On days with more liquid water the enhanced tropospheric opacity attenuates the radiation originating from the middle atmosphere, leading to a lower line amplitude. Therefore it is more likely that spectra from single measurement cycles do not meet the minimal signal to noise ratio conditions (ratio between line amplitude and measurement noise), so that fewer single measurements contribute to the daily average spectra. This leads to a higher noise level on the spectra input to the retrieval algorithm. Under such conditions the right panels in Figs. 10 and 11 (the dashed lines in Fig. 12) better characterise the error than the left panels (the full lines). By coincidence, due to the definition of single and double sideband noise temperature and the factor of improvement in the receiver noise, the typical noise levels of spectra measured with the new single sideband receiver with less integration time at the respective sky positions (zonal and meridional wind measured, in contrast to only zonal wind with the old receiver) are similar to those of spectra measured with the double sideband receiver before the upgrade described in Sect. 2.

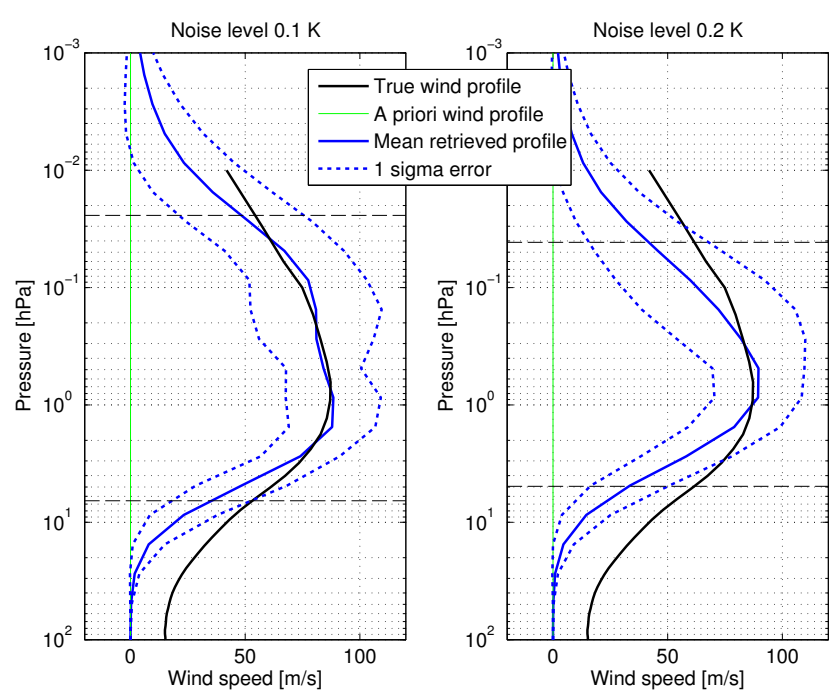

Figure 10. Monte Carlo error simulations for measurements taken with the old double sideband receiver for typical noise levels. The results in the left panel correspond to days with clear sky or dry clouds (noise level $0.1 \mathrm{~K}$ ) while the results shown in the right panel correspond to days with higher opacity as in the case of wet clouds (noise level $0.2 \mathrm{~K}$ ). The dashed lines delimit the trustable altitude region. The true profile is the wind profile that was used to generate the synthetic spectra that were fed to the retrieval algorithm.

\section{Evaluation of possible sources for bias errors}

In addition to the random error analysis, possible sources of bias in the retrieved wind have been extensively studied based on Monte Carlo simulations. The influence of errors related to uncertainties in the forward model parameters is displayed in Fig. 11. For these simulations the following quantities were perturbed: the centre frequency of the emis- 


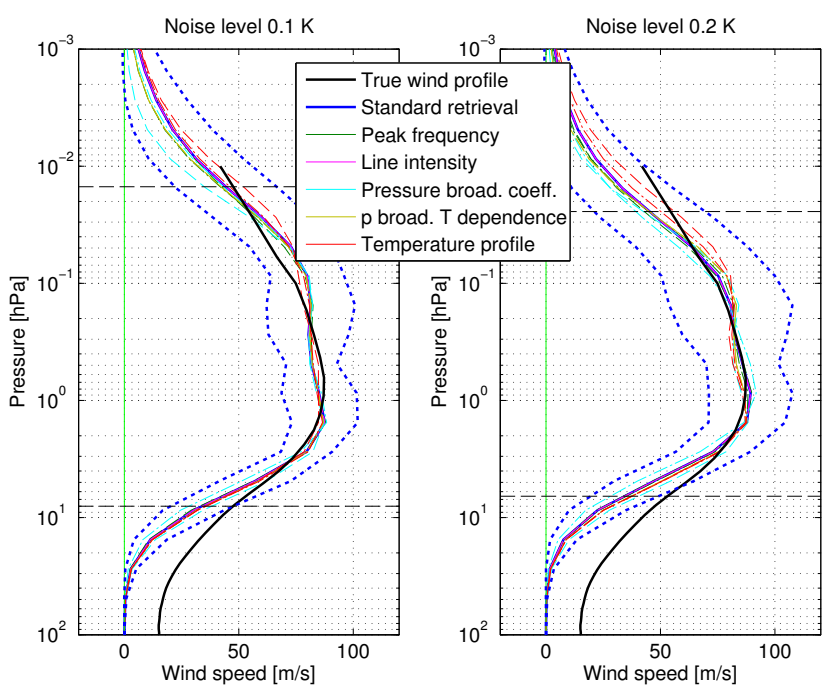

Figure 11. As Fig. 10 but for the new single sideband receiver. This plot moreover contains the mean profiles resulting from retrievals with perturbed forward model parameters.

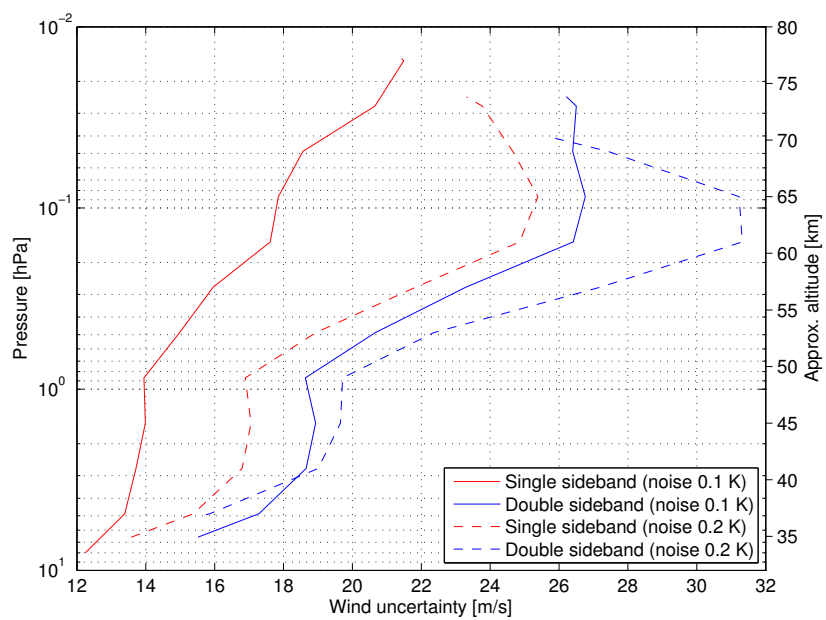

Figure 12. Standard deviation of the resulting profiles in the Monte Carlo simulation displayed in Figs. 10 and 11.

sion line according to the uncertainty indicated in the spectroscopy catalog used (Pickett et al., 1998), the line intensity by $\pm 10 \%$, the pressure broadening coefficient by $\pm 10 \%$, the temperature dependency coefficient of the pressure broadening by $\pm 10 \%$ and the temperature profile by $\pm 3 \%$. It appears that none of these parameters can cause a significant bias in the retrieved wind.

Another possible source of bias could be an instrumental baseline. The spectra from WIRA contain a baseline that is dominated by a standing wave originating from reflections at the ambient temperature calibration target and the horn antenna. This oscillation can be assessed when using data from the broadband spectrometer and is corrected in the routine data processing where possible (the broadband spectrometer

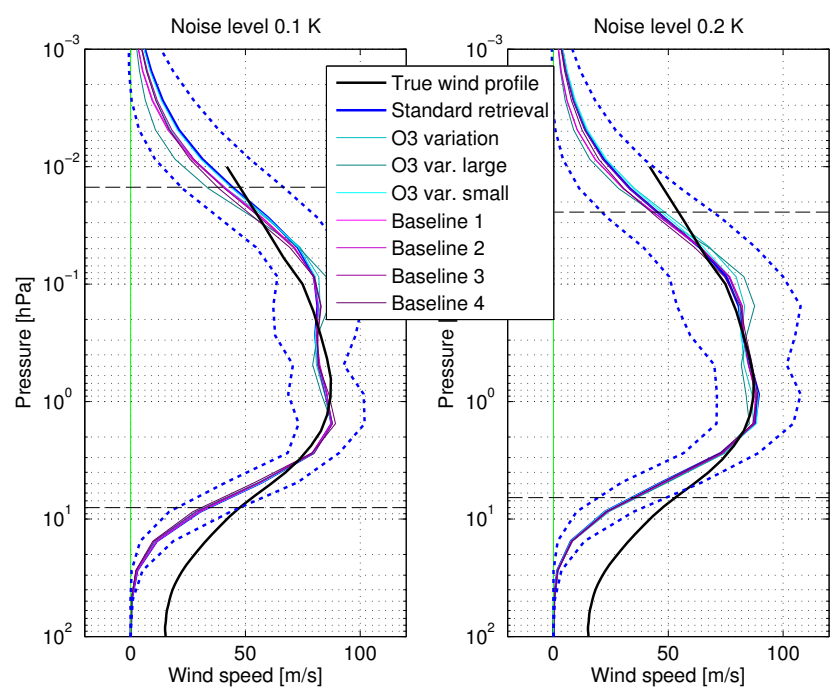

Figure 13. As Fig. 11. Instead of the results for perturbed forward model parameters, the mean profiles for situations with atmospheric ozone profiles strongly deviating from the a priori are plotted. The graph also contains the mean profiles for input spectra which are affected by a baseline with a typical amplitude and period for WIRA. Baselines 1, 2, 3 and 4 refer to different phases, i.e. are shifted in spectral dimension.

board was not running before September 2012; since then the baseline correction has succeeded in more than $90 \%$ of cases). The amplitude of the baseline was found to be $0.16 \mathrm{~K}$ on average on the spectra measured with the single sideband receiver and is expected to be significantly smaller for the double sideband measurements because of the phase mismatch of the baseline in the signal and image sideband. The influence of baselines with $0.16 \mathrm{~K}$ amplitude and a period corresponding to the standing wave between the calibration target and the antenna has been simulated for different phase shifts. The results in Fig. 13 illustrate that the baseline of WIRA is uncritical for the wind measurements in any situation.

As mentioned in Sect. 3, the influence of frequency independent calibration inaccuracies can be neglected for the wind retrieval due to the antisymmetric behaviour of the rows of the Jacobian. Frequency-dependent calibration inaccuracies are expected to be very small in our narrow band application. However, the results in Fig. 13 show that even such inaccuracies would not significantly bias the wind measurements as their effect on the measured spectra would be similar to that of a baseline.

Atmospheric ozone profiles that are far away from the a priori profile assumed in the retrieval might be compensated by other variables. Therefore the effect on the retrieved wind has been simulated for three situations. The results are also displayed in Fig. 13. The bases of these simulations were ozone profiles reduced by $10 \%$, with a vertical oscillation with a wavelength of $20 \mathrm{~km}$ and an amplitude of $5 \%$ of 

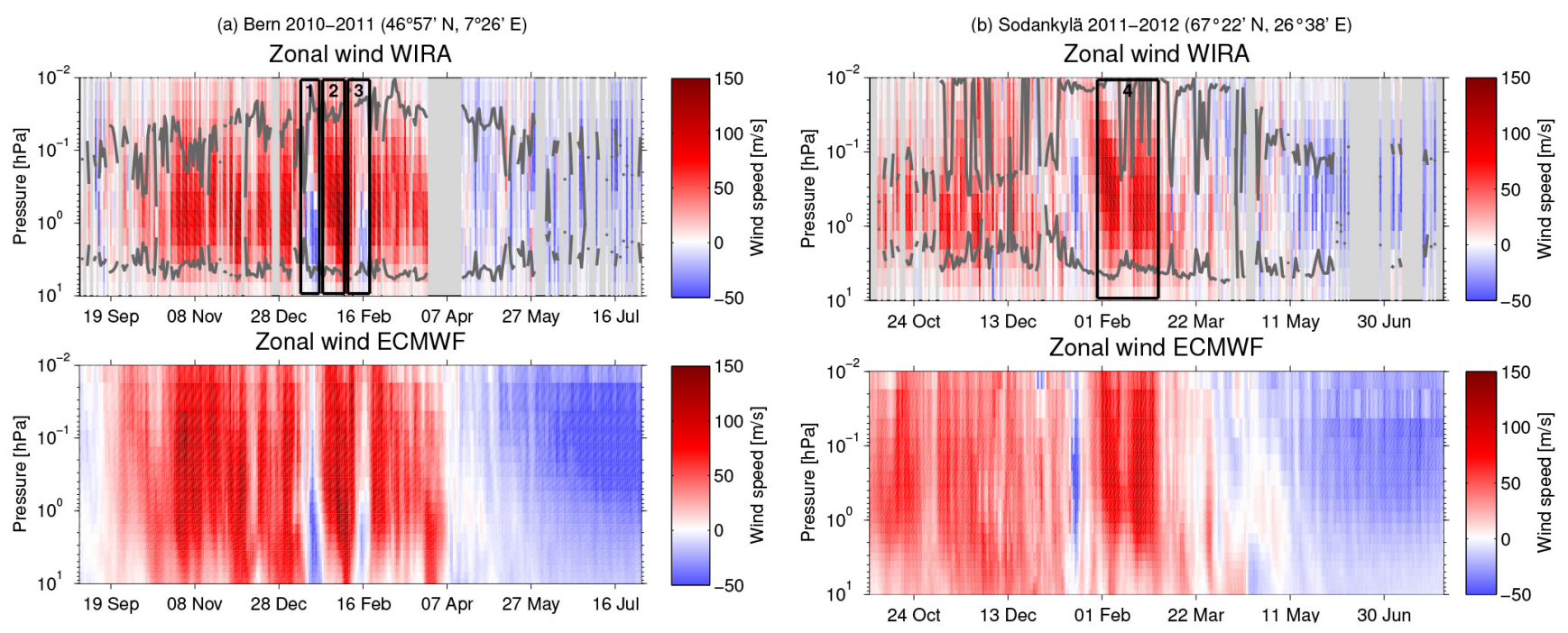

(c) Provence $2012-2013\left(43^{\circ} 56^{\prime} \mathrm{N}, 5^{\circ} 43^{\prime} \mathrm{E}\right)$

Zonal wind WIRA
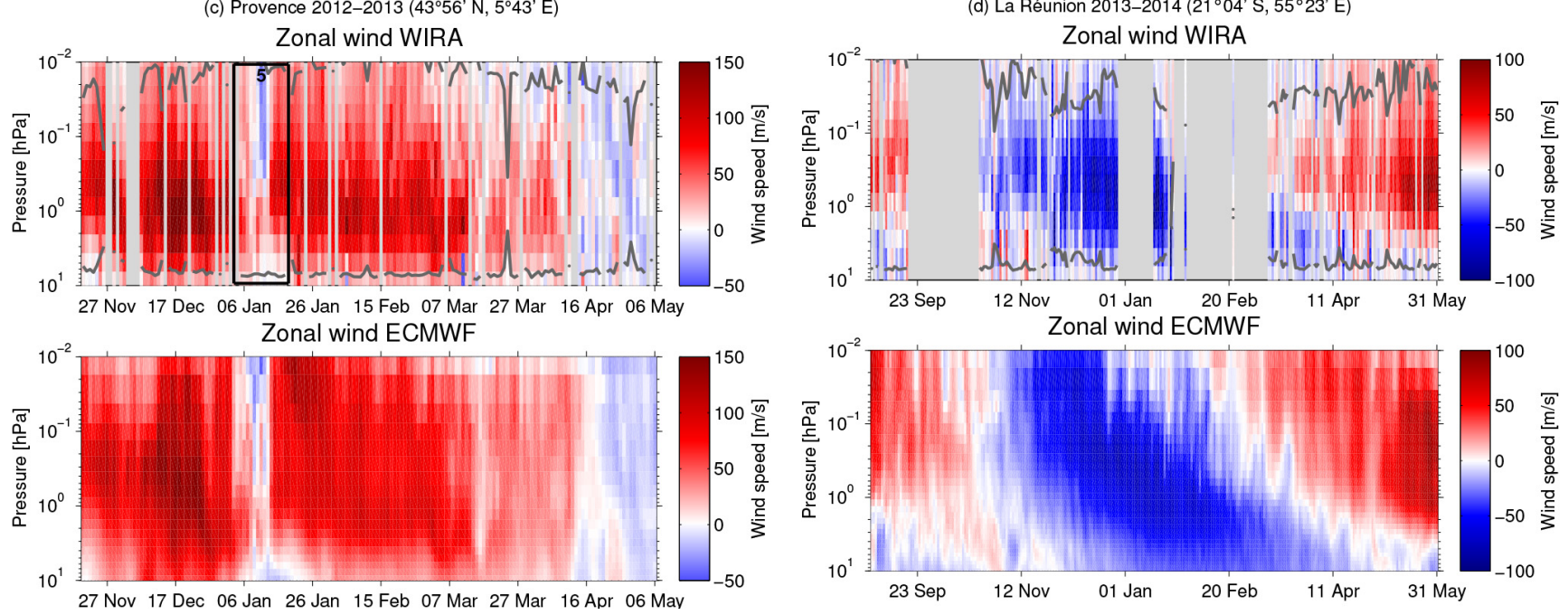

Figure 14. Zonal wind time series measured by WIRA at four different locations compared to ECMWF operational analysis data. The grey lines delimit the trustable altitude range of the retrieved data. The black rectangles mark the dynamic episodes described in the text.

the ozone mixing ratio (referred to as "ozone variation" in Fig. 13), a control run with $1 \%$ reduction and $0.5 \%$ oscillation (referred to as "weak") and an extreme case with $30 \%$ reduction and $10 \%$ oscillation (referred to as "strong"). It appears that even such drastic differences between ozone a priori and true profile have very little effect on the wind retrieval.

Finally, one might think that differences in ozone profiles measured under different azimuths could have an effect on the wind profiles determined by WIRA, because their determination relies on the combination of measurements taken under two different azimuth angles (west and east for zonal, north and south for meridional wind). This effect has been quantified to be smaller than $1 \mathrm{~m} \mathrm{~s}^{-1}$ on every altitude level when assuming that the ozone profiles between the two directions used for the wind retrieval are smaller than $5 \%$, which seems a reasonable assumption with our observation geom- etry. For these calculations the part of the averaging kernel matrix relating ozone to wind has been used.

As mentioned in Sect. 2, the effect of fluctuations of the frequency references of the receiver on the measured wind is marginal.

\section{Measurements from different locations}

A prototype of WIRA has been operational since September 2010. Although major upgrades as described in Sect. 2 have significantly improved the quality of the data, the measurements of the first phase before autumn 2012 (double sideband receiver) remain perfectly usable. The most notable difference is that with the double sideband receiver more integration time was needed to acquire the data, thus meridional wind was not measured. Moreover, the sensitive alti- 

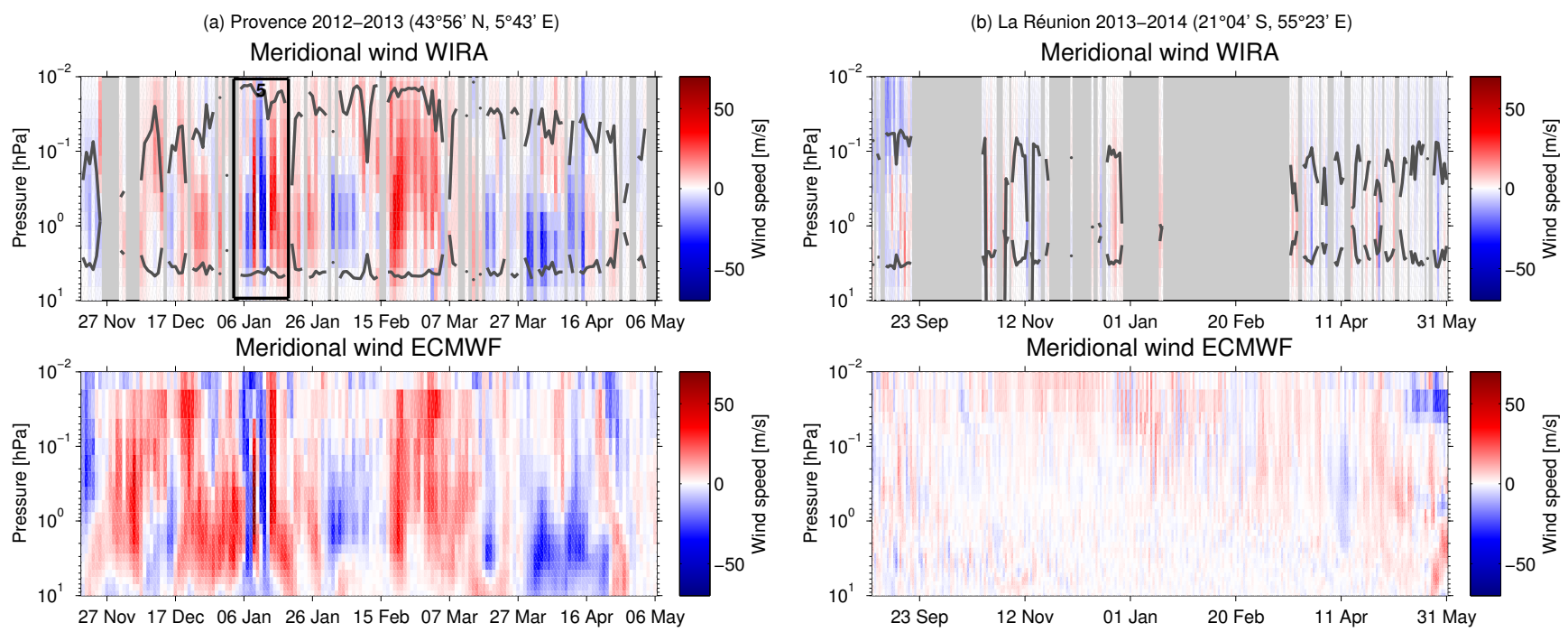

Figure 15. Meridional wind time series measured by WIRA at two different locations compared to ECMWF operational analysis data. The grey lines delimit the trustable altitude range of the retrieved data. The black rectangle marks a dynamic episode described in the text.

tude range is smaller, the altitude resolution is slightly lower and the wind uncertainties are higher.

Before the upgrade to the single sideband receiver the instrument has been operated at midlatitudes (Bern, $46^{\circ} 57^{\prime} \mathrm{N} / 7^{\circ} 26^{\prime} \mathrm{E}, 1$ September 2010 to 31 July 2011) and high latitudes (Sodankylä, $67^{\circ} 22^{\prime} \mathrm{N} / 26^{\circ} 38^{\prime} \mathrm{E}, 1$ October 2011 to 31 July 2012) during almost one annual cycle. After this upgrade another set of midlatitude data has been collected (Observatoire de Haute-Provence, $43^{\circ} 56^{\prime} \mathrm{N} / 5^{\circ} 43^{\prime} \mathrm{E}, 20$ November 2012 to 6 May 2013) during a measurement campaign in the framework of the ARISE project $^{2}$. In autumn 2013 WIRA was moved to Observatoire du Maïdo on La Réunion island $\left(21^{\circ} 04^{\prime} \mathrm{S} / 55^{\circ} 23^{\prime} \mathrm{E}\right.$, 1 September 2013 until today) where measurements of tropical middle-atmospheric wind have successfully been performed.

\subsection{Dynamical features in the data sets from the Arctic to the tropics as observed by WIRA}

The time series of daily averaged wind measurements from WIRA from all measurement campaigns in comparison with the operational analysis data from ECMWF are summarised in Figs. 14 and 15. The grey lines delimit the trustable altitude range of the retrieved data as defined in Sect. 4.2. Data above and below these limits shall not be considered. The three major data gaps in the time series from La Réunion were due to a loose connector (twice) and an interruption of the measurement activity during the overpass of the strong tropical cyclone Bejisa.

\footnotetext{
${ }^{2}$ ARISE is a European project for the development of research infrastructure for atmospheric dynamics and extreme events. For more information: http://arise-project.eu.
}

The seasonal pattern of the zonal wind with the slow wind reversal around equinox is visible in the data from every midand high-latitude measurement site (Fig. 14a-c). Despite the low amount of data collected on La Réunion until now, the signature of the semi-annual oscillation is clearly visible in the mesosphere (Fig. 14d)

Interesting changes in the short time dynamical structures have also been observed by WIRA. For instance, an overpass of the edge of the polar vortex over central Europe during the vortex displacement event in January 2011 caused a reversal of the zonal wind over Bern (rectangle 1 in Fig. 14a). The recovery towards the westward circulation which dominates in winter first occurred in the mesosphere before it also started in the stratosphere (rectangle 2 in Fig. 14a). A few days later, in mid-February 2011, another reversal of the mean flow was observed during the sudden stratospheric minor warming ${ }^{3}$ (rectangle 3 in Fig. 14a). Interestingly, this wind reversal was confined to the stratosphere and the very low parts of the mesosphere. In the higher parts of the mesosphere the mean flow was strongly decelerated, but there was no reversal of the zonal wind direction throughout the entire middle atmosphere as had been observed at the overpass event of mid-January 2011.

At the high-latitude station of Sodankylä a speedup of the eastward circulation in the recovery after the major sudden stratospheric warming of January 2012 is clearly visible in the data measured by WIRA (rectangle 4 in Fig. 14b). A closer look at the extension and shape of the polar vortex in model data reveals that the two episodes of high zonal wind

\footnotetext{
${ }^{3}$ In the present paper the classification of sudden stratospheric warmings is made according to the definition by McInturff (1978) based on the temperature and zonal wind data from ECMWF operational analysis.
} 

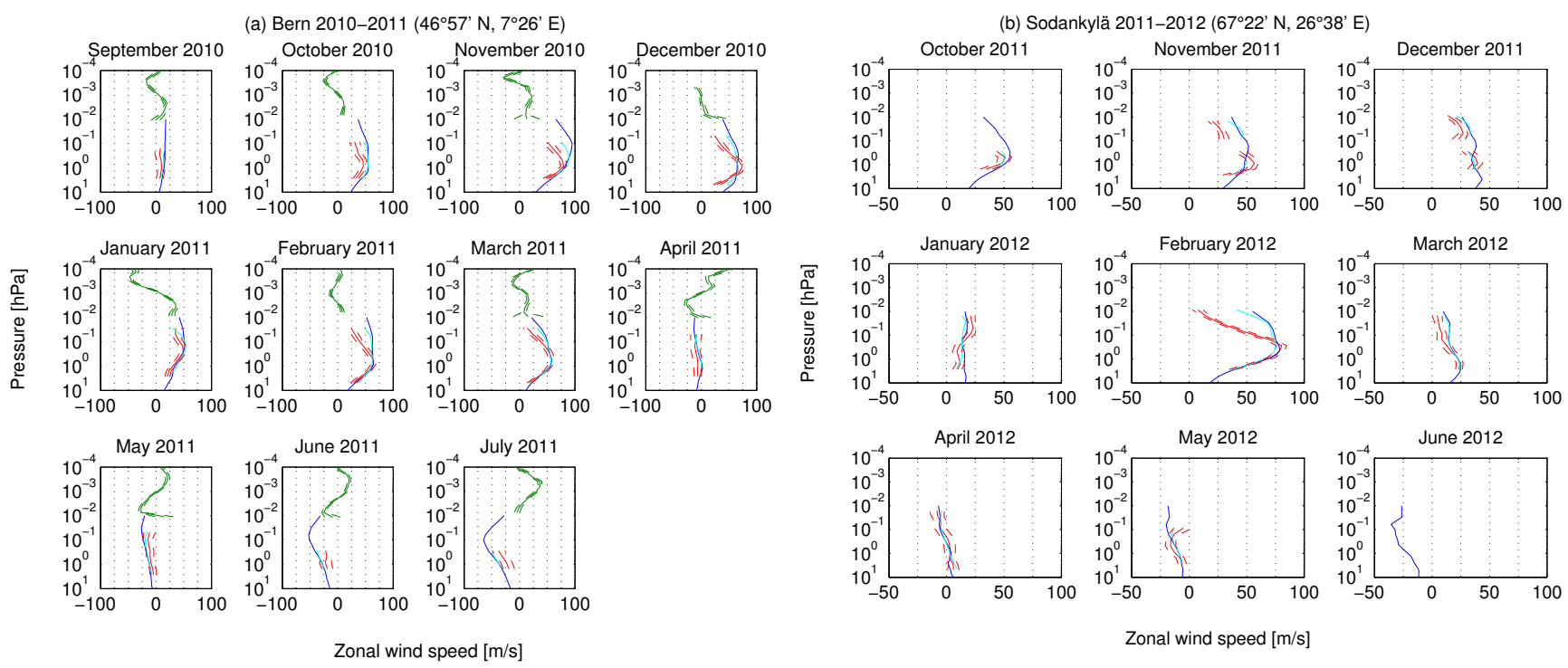

Figure 16. Monthly mean profiles of zonal wind measured by the old WIRA double sideband receiver (red) compared to ECMWF operational analysis data (blue), to the ECMWF profile convolved with WIRA's averaging kernels (cyan) and to TIDI data (green). The dashed lines represent the error estimates for the averaged measurement data.

speeds in rectangle 4 coincide with periods where the edge of the vortex was unusually close to Sodankylä.

At the midlatitude station of Haute-Provence, direct observations of the dynamics were made during the sudden stratospheric warming event of January 2013 (rectangle 5 in Fig. 14c). They show that the zonal wind direction reversed to westward only in the mesosphere and remained eastward in the stratosphere. This is a clear contrast to the warming event of February 2011 observed at the other midlatitude station (Bern) described above, where the wind reversal was confined to the lower parts of the middle atmosphere. When comparing the measurements during the January 2013 event to ECMWF model data it appears that in this special dynamical situation the zonal wind velocities measured by WIRA were slightly higher. This difference is even more notable as the ECMWF zonal wind velocities in the mesosphere are generally lower than the ones measured by WIRA (see Sect. 5.2). The January 2013 event was also the first sudden stratospheric warming during which both the zonal and the meridional wind components have been continuously measured, thus providing a complete picture of the horizontal wind field. These observations show how the mean flow at midlatitudes inverted its direction from eastward to westward by turning through the meridional direction during the SSW, which resulted in unusually high meridional daily average wind velocities of beyond $50 \mathrm{~m} \mathrm{~s}^{-1}$ (rectangle 5 in Figs. 14c and 15a). Fair agreement in the timing of the meridional wind reversals exists between WIRA and ECMWF.

\subsection{Average wind profiles of WIRA compared to ECMWF and TIDI}

As is seen in Figs. 14 and 15, the agreement between the wind measured by WIRA and the ECMWF operational analysis data is good, especially in the stratosphere. However, the mesospheric zonal wind speed measured by WIRA is lower than the model wind speed from ECMWF above approximatively $0.3 \mathrm{hPa}$, which becomes more obvious when plotting monthly mean profiles of WIRA and ECMWF data as shown in Figs. 16 and 17. The discrepancy in mesospheric zonal wind from WIRA and the ECMWF data convolved with WIRA's averaging kernels can be as high as $50 \%$ in the mesosphere. Figure 18 shows the relative difference to the convolved ECMWF data for the mean profiles over the entire campaigns of Bern (1 September 2010 to 31 July 2011), Sodankylä (1 October 2011 to 31 July 2012) and Haute-Provence (20 November 2012 to 6 May 2013). The results from La Réunion are not plotted because the average zonal wind profile is very close to zero, so that the relative differences do not deliver any meaningful information. All three difference profiles follow a similar pattern, with agreement within $10 \%$ in the stratosphere and significantly higher ECMWF wind speeds above $0.3 \mathrm{hPa}$.

The mesospheric zonal wind discrepancy between WIRA and ECMWF also appears when convolved data are compared. It can thus not be attributed to an artefact of WIRA averaging in smaller wind velocities from the higher parts of the mesosphere due to the limited altitude resolution. The authors do not see any reason why WIRA's zonal wind measurements should suffer from a systematical error in the 

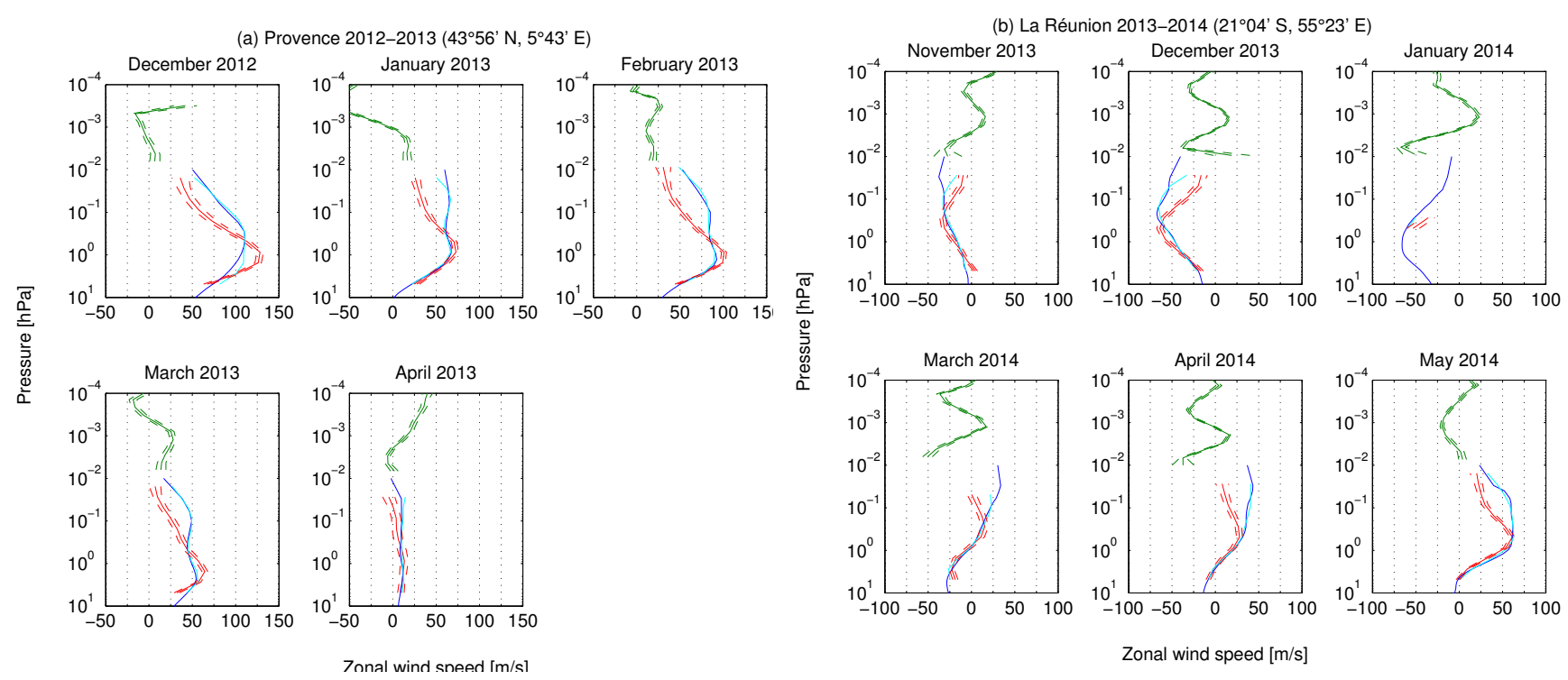

Figure 17. Monthly mean profiles of zonal wind measured by the new WIRA single sideband receiver (red) compared to ECMWF operational analysis data (blue), to the ECMWF profile convolved with WIRA's averaging kernels (cyan) and to TIDI data (green). The dashed lines represent the error estimates for the averaged measurement data.

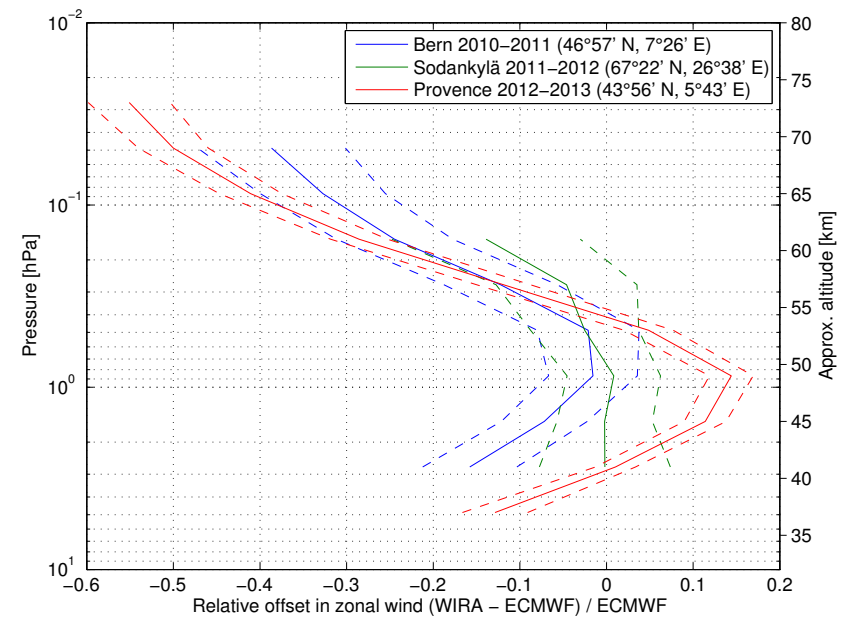

Figure 18. Relative difference between the average profiles of WIRA and ECMWF for the measurement campaigns in Bern, Sodankylä and Haute-Provence. The dashed lines represent the errors of the mean wind profiles from WIRA. The data from ECMWF have been convolved with WIRA's averaging kernels. Results are only shown within the trustable altitude range of the retrieval.

mesosphere but not in the stratosphere. Indeed, the entire altitude range is measured simultaneously and with the same hardware. The retrieval algorithm encompasses the entire atmosphere from $10^{3}$ to $10^{-3} \mathrm{hPa}$. As shown in Sect. 4.1, it can also be excluded that the discrepancy between WIRA and ECMWF stems from the influence of the a priori information. This statement is supported by a complementary test retrieval using a constant a priori wind profile of $100 \mathrm{~m} \mathrm{~s}^{-1}$ instead of the standard $0 \mathrm{~m} \mathrm{~s}^{-1}$ a priori for 1 month of operational data (February 2013). The difference between the resulting profiles retrieved with the two a priori assumptions $\left(0\right.$ or $\left.100 \mathrm{~m} \mathrm{~s}^{-1}\right)$ was only $\leq 4 \mathrm{~ms}^{-1}(\leq 4 \%)$ in the mesosphere.

The measurement data from the satellite-borne interferometer TIDI (Killeen et al., 2006), which are generally available above $80 \mathrm{~km}\left(10^{-2} \mathrm{hPa}\right)$, have also been added to the plots in Figs. 16 and 17. Because of the high-latitude location of Sodankylä, not enough overpasses of TIDI were registered to allow for meaningful average wind profiles. There is no altitude overlap with WIRA or ECMWF data, but qualitatively TIDI also seems to suggest that ECMWF overestimates the zonal wind speeds in the mesosphere, as one would not expect an abrupt change of the wind speed with altitude. A possible explanation might be that ECMWF has the main constraints coming from the troposphere and lower stratosphere and gets no mesospheric data input.

\section{Conclusions}

WIRA had already proved the ability of ground-based microwave radiometry to measure middle-atmospheric wind. The new retrieval algorithm based on an optimal estimation inversion of the atmospheric radiative transfer model allows a much better characterisation of the altitude dependence of the wind profile information and of the errors in general. The instrument's signal to noise ratio has been strongly improved by an upgrade. Not only did this improve the precision of the wind measurements, but since then half of the integration time on the sky can also be used for the measurement of 
the meridional wind to obtain a full picture of the horizontal wind field of the atmosphere.

With measurements at four different sites between $67^{\circ} \mathrm{N}$ and $21^{\circ} \mathrm{S}$, including direct observations of sudden stratospheric warmings and displacement events of the polar vortex, the data set collected by WIRA offers a great number of opportunities for further atmospheric research.

The comparison to ECMWF model data reveals agreement within the errors of WIRA in the daily averages of meridional wind. The zonal winds below approximately $0.3 \mathrm{hPa}$ are also in good agreement. A notable difference is that ECMWF wind speeds in the mesosphere, where the model gets virtually no measured input data, are by up to $50 \%$ higher than the ones measured by WIRA.

Acknowledgements. This work has been supported by the Swiss National Science Foundation grant number 200020-146388. We acknowledge ECMWF for the operational analysis data as well as NASA and University of Michigan for the TIDI wind data and NASA for the Aura MLS temperature profiles. We especially thank the staff of the Observatoire du Maïdo, of the Observatoire de Haute-Provence and of the Finnish Meteorological Institute in Sodankylä for the hospitality and support during the measurement campaigns.

Edited by: A. Stoffelen

\section{References}

Angot, G., Keckhut, P., Hauchecorne, A., and Claud, C.: Contribution of stratospheric warmings to temperature trends in the middle atmosphere from the lidar series obtained at HauteProvence Observatory (44 degrees N), J. Geophys. Res.-Atmos., 117, D21102, doi:10.1029/2012JD017631, 2012.

Baldwin, M. and Dunkerton, T.: Stratospheric harbingers of anomalous weather regimes, Science, 294, 581-584, doi:10.1126/science.1063315, 2001.

Baron, P., Murtagh, D. P., Urban, J., Sagawa, H., Ochiai, S., Kasai, Y., Kikuchi, K., Khosrawi, F., Körnich, H., Mizobuchi, S., Sagi, K., and Yasui, M.: Observation of horizontal winds in the middle-atmosphere between $30^{\circ} \mathrm{S}$ and $55^{\circ} \mathrm{N}$ during the northern winter 2009-2010, Atmos. Chem. Phys., 13, 6049-6064, doi:10.5194/acp-13-6049-2013, 2013.

Baumgarten, G.: Doppler Rayleigh/Mie/Raman lidar for wind and temperature measurements in the middle atmosphere up to 80 km, Atmos. Meas. Tech., 3, 1509-1518, doi:10.5194/amt-31509-2010, 2010.

Buehler, S. A., Eriksson, P., Kuhn, T., von Engeln, A., and Verdes, C.: ARTS, the atmospheric radiative transfer simulator, J. Quant. Spectrosc. Ra., 91, 65-93, doi:10.1016/j.jqsrt.2004.05.051, 2005.

Buehler, S. A., Eriksson, P., and Lemke, O.: Absorption lookup tables in the radiative transfer model ARTS, J. Quant. Spectrosc. Ra., 112, 1559-1567, doi:10.1016/j.jqsrt.2011.03.008, 2011.

Chu, Y. H., Su, C. L., Larsen, M. F., and Chao, C. K.: First measurements of neutral wind and turbulence in the meso- sphere and lower thermosphere over Taiwan with a chemical release experiment, J. Geophys. Res.-Space, 112, A02301, doi:10.1029/2005JA011560, 2007.

Dumitru, C., Hocke, K., Kämpfer, N., and Calisesi, Y.: Comparison and validation studies related to ground-based microwave observations of ozone in the stratosphere and mesosphere, J. Atmos. Sol.-Terr. Phy., 68, 745-756, doi:10.1016/j.jastp.2005.11.001, 2006.

Eriksson, P., Jimenez, C., and Buehler, S.: Qpack, a general tool for instrument simulation and retrieval work, J. Quant. Spectrosc. Ra., 91, 47-64, doi:10.1016/j.jqsrt.2004.05.050, 2005.

Eriksson, P., Buehler, S., Davis, C., Emde, C., and Lemke, O.: ARTS, the atmospheric radiative transfer simulator, version 2, J. Quant. Spectrosc. Ra., 112, 1551-1558, doi:10.1016/j.jqsrt.2011.03.001, 2011.

Finger, F. G., Gelman, M. E., Schmidlin, F. J., Leviton, R., and Kennedy, B. W.: Compatibility of Meteorological Rocketsonde Data as Indicated by International Comparison Tests, J. Atmos. Sci., 32, 1705-1714, doi:10.1175/15200469(1975)032<1705:COMRDA>2.0.CO;2, 1975.

Goldberg, R. A., Fritts, D. C., Williams, B. P., Lübken, F.J., Rapp, M., Singer, W., Latteck, R., Hoffmann, P., Müllemann, A., Baumgarten, G., Schmidlin, F.-J., She, C., and Krueger, D. A.: The MaCWAVE/MIDAS rocket and groundbased measurements of polar summer dynamics: overview and mean state structure, Geophys. Res. Lett., 31, L24S02, doi:10.1029/2004GL019411, 2004.

Hardiman, S. C., Butchart, N., Charlton-Perez, A. J., Shaw, T. A., Akiyoshi, H., Baumgaertner, A., Bekki, S., Braesicke, P., Chipperfield, M., Dameris, M., Garcia, R. R., Michou, M., Pawson, S., Rozanov, E., and Shibata, K.: Improved predictability of the troposphere using stratospheric final warmings, J. Geophys. Res.Atmos., 116, D18113, doi:10.1029/2011JD015914, 2011.

Hoffmann, P., Singer, W., Keuer, D., Hocking, W. K., Kunze, M., and Murayama, Y.: Latitudinal and longitudinal variability of mesospheric winds and temperatures during stratospheric warming events, J. Atmos. Sol.-Terr. Phy., 69, 2355-2366, doi:10.1016/j.jastp.2007.06.010, 2007.

Jacobi, C., Fröhlilch, K., Viehweg, C., Stober, G., and Kürschner, D.: Midlatitude mesosphere/lower thermosphere meridional winds and temperatures measured with meteor radar, Adv. Space Res., 39, 1278-1283, doi:10.1016/j.asr.2007.01.003, 2007.

Killeen, T. L., Wu, Q., Solomon, S. C., Ortland, D. A., Skinner, W. R., Niciejewski, R. J., and Gell, D. A.: TIMED Doppler interferometer: overview and recent results, J. Geophys. Res.Space, 111, A10S01, doi:10.1029/2005JA011484, 2006.

Liebe, H. J., Hufford, G. A., and Cotton, M. G.: Propagation modeling of moist air and suspended water/ice particles at frequencies below $1000 \mathrm{GHz}$, in: AGARD 52nd Specialists' Meeting of the Electromagnetic Wave Propagation Panel, Palma de Mallorca, Spain, 3.1-3.10, 1993.

Marquardt, D.: An algorithm for least-squares estimation of nonlinear parameters, J. Soc. Ind. Appl. Math., 11, 431-441, doi:10.1137/0111030, 1963.

McInturff, R. M.: Stratospheric warmings: Synoptic, dynamic and general-circulation aspects, Tech. rep., NASA Reference Publication 1017, Washington DC, 1978.

Nicolls, M. J., Varney, R. H., Vadas, S. L., Stamus, P. A., Heinselman, C. J., Cosgrove, R. B., and Kelley, M. C.: Influence of 
an inertia-gravity wave on mesospheric dynamics: A case study with the Poker Flat Incoherent Scatter Radar, J. Geophys. Res.Atmos., 115, doi:10.1029/2010JD014042, 2010.

Palm, M., Hoffmann, C. G., Golchert, S. H. W., and Notholt, J.: The ground-based MW radiometer OZORAM on Spitsbergen - description and status of stratospheric and mesospheric $\mathrm{O}_{3}$-measurements, Atmos. Meas. Tech., 3, 1533-1545, doi:10.5194/amt-3-1533-2010, 2010.

Pickett, H. M., Poynter, R. L., Cohen, E. A., Delitsky, M. L., Pearson, J. C., and Muller, H. S. P.: Submillimeter, Millimeter, and Microwave Spectral Line Catalog, J. Quant. Spectrosc. Ra., 60, 883-890, doi:10.1016/S0022-4073(98)00091-0, 1998.

Press, W. H., Teukolsky, S. A., Vetterling, W. T., and Flannery, B. P.: Numerical Recipes 3rd Edition: The Art of Scientific Computing, 3rd Edn., Cambridge University Press, New York, NY, USA, 2007.

Rodgers, C. D.: Inverse methods for atmospheric sounding: theory and practice, in: Series on Atmospheric, Oceanic and Planetary Physics, Vol. 2, World Scientific, Singapore, reprint 2008, 2000.

Rosenkranz, P. W.: Absorption of Microwaves by Atmospheric Gases, in: Atmospheric Remote Sensing By Microwave Radiometry, edited by: Janssen, M. A., p. 37, 1993.

Rosenkranz, P. W.: Water vapor microwave continuum absorption: A comparison of measurements and models, Radio Sci., 33, 919 928, doi:10.1029/98RS01182, 1998

Rüfenacht, R., Kämpfer, N., and Murk, A.: First middleatmospheric zonal wind profile measurements with a new ground-based microwave Doppler-spectro-radiometer, Atmos. Meas. Tech., 5, 2647-2659, doi:10.5194/amt-5-2647-2012, 2012.
Schneebeli, M. and Mätzler, C.: A calibration scheme for microwave radiometers using tipping curves and kalman filtering, IEEE T. Geosci. Remote, 47, 4201-4209, doi:10.1109/TGRS.2009.2023784, 2009.

Stähli, O., Murk, A., Kämpfer, N., Mätzler, C., and Eriksson, P.: Microwave radiometer to retrieve temperature profiles from the surface to the stratopause, Atmos. Meas. Tech., 6, 2477-2494, doi:10.5194/amt-6-2477-2013, 2013.

Tschanz, B., Straub, C., Scheiben, D., Walker, K. A., Stiller, G. P., and Kämpfer, N.: Validation of middle-atmospheric campaignbased water vapour measured by the ground-based microwave radiometer MIAWARA-C, Atmos. Meas. Tech., 6, 1725-1745, doi:10.5194/amt-6-1725-2013, 2013.

Waters, J., Froidevaux, L., Harwood, R., Jarnot, R., Pickett, H., Read, W., Siegel, P., Cofield, R., Filipiak, M., Flower, D., Holden, J., Lau, G., Livesey, N., Manney, G., Pumphrey, H., Santee, M., Wu, D., Cuddy, D., Lay, R., Loo, M., Perun, V., Schwartz, M., Stek, P., Thurstans, R., Boyles, M., Chandra, K., Chavez, M., Chen, G., Chudasama, B., Dodge, R., Fuller, R., Girard, M., Jiang, J., Jiang, Y., Knosp, B., LaBelle, R., Lam, J., Lee, K., Miller, D., Oswald, J., Patel, N., Pukala, D., Quintero, O., Scaff, D., Van Snyder, W., Tope, M., Wagner, P., and Walch, M.: The Earth Observing System Microwave Limb Sounder (EOS MLS) on the Aura satellite, IEEE T. Geosci. Remote, 44, 10751092, doi:10.1109/TGRS.2006.873771, 2006. 